\title{
Co-Processing of Light Gasoil and Used Cooking Oil in a Hydrotreatment Industrial Unit
}

\author{
De Paz Carmona $\mathrm{H}^{1 *}$, Brito Alayón $\mathrm{A}^{1}$ and Macías Hernández JJ ${ }^{2}$ \\ ${ }^{1}$ Chemical Engineering Department,University of La Laguna (ULL), Spain \\ ${ }^{2}$ Refinery Cepsa Tenerife, Spain
}

*Corresponding author: De Paz Carmona H, Faculty of Chemistry, Chemical Engineering Deparment, University of La Laguna (ULL),Con. San Frco. De Paula, San Cristóbal de La Laguna, Spain.

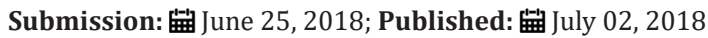

\section{Introduction}

The European Union (UE) renewable energy requirements for next years, are working as engine to develop new, more efficient and environmentally friendly bio-fuels. The hydro-treated vegetable oil (HVO) or Green diesel is a paraffinic diesel fuel produced via catalytic hydro-treatment of vegetable oils at high temperature and pressure [1].The co-processing of triglycerides feedstocks such used cooking oils (UCO), in an industrial hydrodesulphurization unit could be very attractive for refineries. It is because not only can be employed the existing installations [2], but it is obtained a bio-fuel that is integrated with the desulphurized gasoil, improving some of their properties such as density at $15{ }^{\circ} \mathrm{C}$ and flammability.At the industrial conditions $\left(350-370^{\circ} \mathrm{C}\right.$ and $70-80$ bar $)$, the triglycerides are hydrogenated according with the pathways of Figure 1.

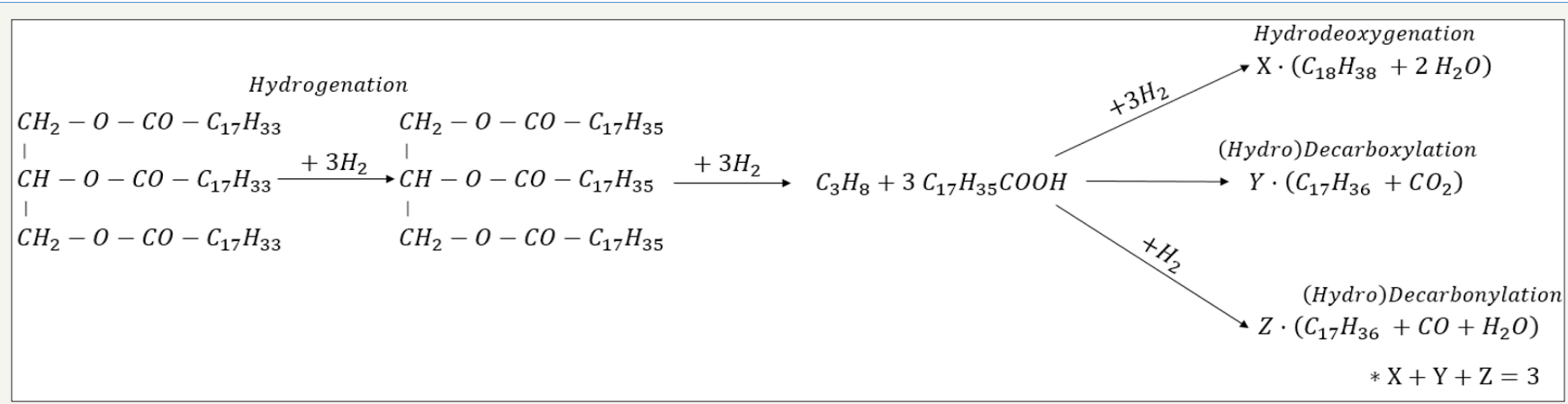

Figure 1: Triglycerides reactions pathways.

\section{Material and Methods}

Table 1: Operating conditions used in co-processing experiments.

\begin{tabular}{|c|c|c|}
\hline Parameter $\backslash$ Experiment $\mathrm{Nr}$ & 1 & 2 \\
\hline Temperature ${ }^{\circ} \mathrm{C}$ & 350 & $370-380$ \\
\hline Pressure, MPa & $7.0-7.2$ & $7.0-7.2$ \\
\hline WHSV, $\mathrm{h}^{-1}$ & 0.85 & $1.30-1.60$ \\
\hline $\mathrm{H} 2$ to oil, $\mathrm{Nl} / \mathrm{l}$ & 220 & 200 \\
\hline UCO, wt.\% & 10 & 5 \\
\hline Feed flowrate, bbl/day & 12,000 & $\begin{array}{c}17,000- \\
21,000\end{array}$ \\
\hline Time of Co-processing, $h$ & 24 & 48 \\
\hline Catalyst & $\mathrm{CoMo} / \mathrm{Al}_{2} \mathrm{O}_{3}$ & $\mathrm{NiMo} / \mathrm{Al}_{2} \mathrm{O}_{3}$ \\
\hline
\end{tabular}

Two experiments of co-processing of light gasoil (LG) and UCO were carried out in an industrial unit of hydrodesulphurization HDS-I of Cepsa refinery in Tenerife. Table 1shows the operating conditions of each experiment.The experimental procedure was divided in two stages: blank run, without vegetable oil, and coprocessing. After reached the steady state in each stage, were recollected and analyzed (density at $15{ }^{\circ} \mathrm{C}$, sulphur and nitrogen content, SimDis, composition, etc.) liquid and gaseous samples.

\section{Results and Discussion}

The main product obtained from UCO hydro-treating was the HVO (75.3-88.1wt.\%), mainly composed by linear paraffins with 15-18 carbon atoms. On the other hand, the by-products produced were water (2.7-15.8wt. \%) and light gases (9.1-8.9wt.\%) [3].To determine the pathways promoted by the catalyst, Figure 2 shows the paraffins distribution in the liquid products.The hydrode- 
oxygenation reaction was promoted rather than HDC pathway in both experiments, particularly with $\mathrm{NiMo} / \mathrm{Al}_{2} \mathrm{O}_{3}$ sulphured catalyst.
This pathway implies a higher consumption of $\mathrm{H}_{2}$ as well as water production instead $\mathrm{CO}$ or $\mathrm{CO}_{2}$.
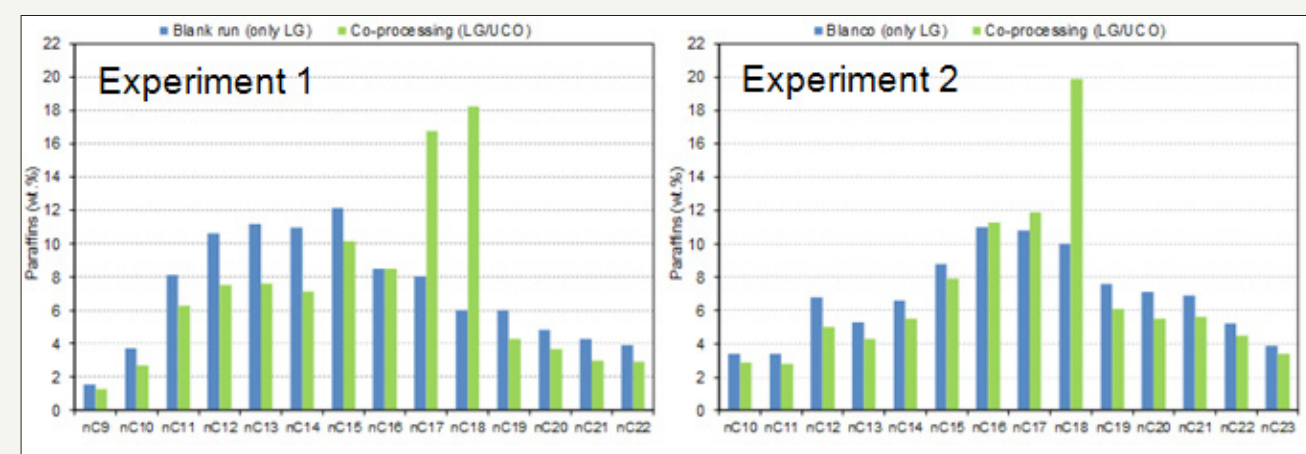

Figure 2: Paraffins distribution. Experimets 1 and 2.

The increment of paraffins produced an alteration of some properties of the desulphurized gasoil. Table 2 shows a comparison between the desulphurized gasoil produced during the blank run and the co-processing.The co-processing of UCO produced a lighter gasoil [3], with a higher value of flammability and cetane index. However, it was observed a little deterioration of some of the cold flow properties as the cloud point.The UCO addition into the feedstock did not produce a significant decrease of the catalyst activity, determined as the capacity of the catalyst to remove the sulphur content from the light gasoil. This behavior probably indicated an adequate number of active site in the catalyst to occur the HDS and de-oxygenations reactions at the same time without mutual inhibition.

Table 2: Desulphurized gasoil properties.

\begin{tabular}{|c|c|c|}
\hline Parameter & Experiment 1 & Experiment 2 \\
\hline Density at $15^{\circ} \mathrm{C}, \mathrm{kg} / \mathrm{L}$ & $-*$ & - \\
\hline Cetane index & + & + \\
\hline Flammability, ${ }^{\circ} \mathrm{C}$ & + & + \\
\hline Cloud point, ${ }^{\circ} \mathrm{C}$ & + & + \\
\hline CFPP, ${ }^{\circ} \mathrm{C}$ & $=$ & $=$ \\
\hline
\end{tabular}

* "+" higher, "-" lower and "=" equalthan the values of the desulphurized diesel from blank run.

\section{Conclusion}

The main product produced during the UCO co-processing was the HVO (75-88wt.\%), composed mainly by linear paraffins with an even number of carbons, which means a promotion of HDO instead HDC pathway. This increment of paraffins produced an improvement of some critical parameter of the desulphurized gasoil as density, cetane index or flammability without a significant interaction with the activity of the catalyst. Thus, the co-processing of UCO is a viable option to obtain bio-fuels at industrial scale using the existing structure of a refinery.

\section{Acknowledgment}

Ministry of Education, Culture and Sports of the Government of SPAIN. FPU grant (AP2012-4532).

\section{References}

1. Bezergianni S, Dimitriadis A (2013) Comparison between different types of renewable diesel. Renewable sustainable Energy Rev 21: 110-116.

2. Al-Sabawi M, Chen J (2012) Hydro processing of biomass-derived oils and their blends with petroleum feed stocks: a review. Energy Fuels 26(9): 5373-5399.

3. De Paz Carmona H, Horáček J, Brito Alayón A, Macías Herández JJ (2018) Suitability of used frying oil for co-processing with atmospheric gas oil. Fuel 214: 165-73.
Creative Commons Attribution 4.0 International License

For possible submissions Click Here

\section{Submit Article}

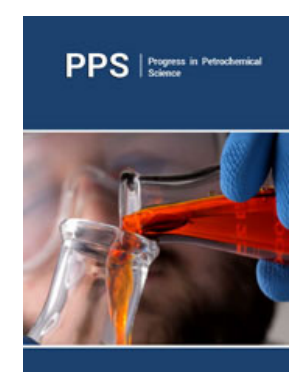

\section{Progress in Petrochemical Science}

\section{Benefits of Publishing with us}

- High-level peer review and editorial services

- Freely accessible online immediately upon publication

- Authors retain the copyright to their work

- Licensing it under a Creative Commons license

- Visibility through different online platforms 